\title{
A Melon Fruit Grading Machine Using a Miniature VIS/NIR Spectrometer: 1. Calibration Models for the Prediction of Soluble Solids Content and Firmness
}

\author{
Sang Ryong Suh, Kyeong-Hwan Lee*, Seung Hwa Yu, Hwa Sun Shin, Young Soo Choi, Soo Nam Yoo \\ Department of Rural and Biosystems Engineering, Chonnam National University, Gwangju, Korea

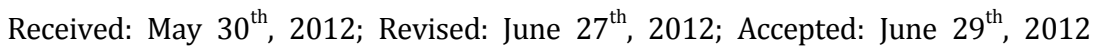

\section{Abstract}

Purpose: This study was conducted to investigate the potential of interactance mode of NIR spectroscopy technology for the estimation of soluble solids content (SSC) and firmness of muskmelons. Methods: Melon samples were taken from local greenhouses in three different harvesting seasons (experiments 1, 2, and 3). The fruit attributes were measured at the 6 points on an equator of each sample where the spectral data were collected. The prediction models were developed using the original spectral data and the spectral data sets preprocessed by 20 methods. The performance of the models was compared. Results: In the prediction of SSC, the highest coefficient of determination $\left(\mathrm{R}_{\mathrm{cv}}{ }^{2}\right)$ values of the cross-validation was 0.755 (standard error of prediction, $\mathrm{SEP}=0.89^{\circ} \mathrm{Brix}$ ) with the preprocessing of normalization with range in experiment 1 . The highest coefficient of determination in the robustness tests, $\mathrm{R}_{\mathrm{rt}}{ }^{2}=0.650$ ( $\mathrm{SEP}=1.03{ }^{\circ}$ Brix), was found when the best model of experiment 3 was evaluated with the data set of experiment 2 . The best $\mathrm{R}_{\mathrm{cv}}{ }^{2}$ for the prediction of firmness was $0.715(\mathrm{SEP}=3.63 \mathrm{~N})$ when no preprocessing was applied in experiment 1 . The highest $\mathrm{R}_{\mathrm{rt}}{ }^{2}$ was $0.404(\mathrm{SEP}=5.30 \mathrm{~N})$ when the best model of experiment 3 was applied to the data set of experiment 1 . Conclusions: From the test results, it can be concluded that the interactance mode of VIS/NIR spectroscopy technology has a great potential to measure SSC and firmness of thick-skinned muskmelons.

Keywords: Firmness, Interactance mode, Muskmelon, Soluble solids content (SSC), VIS/NIR Spectrometer

\section{Introduction}

Muskmelon (Cucumis melo L.) is one of the most widely consumed fruits around the world. In Korea, melon crops are generally grown during winter-spring season in greenhouses where environmental conditions for the crops are controlled precisely with high energy input. Owing to the high production cost of melons and the consumers preferring high quality fruits, the market price of melons is kept in a high level and is various based on the quality of fruits. Therefore, the grading process on harvested melons is essential.

In most of melon farms, harvested melons are graded by experienced inspectors into 3 to 5 levels according to

\footnotetext{
*Comesponding author: Kyeong-Hwan Lee

Tel: +82-62-530-2156; Fax: +82-62-530-2159

E-mail: khlee@jnu.ac.kr
}

their size, appearance, flavor, and taste. Since the grading level is dependent on the long-term experience of the inspectors and their subjective judgement, the manual grading process cannot ensure high accuracy and reliability. Moreover, the tests for estimating taste are conducted on some samples taken from harvested whole fruits by a destructive method. The manual grading process, which is labor-intensive, time-consuming, and inaccurate, cannot meet the requirements of a new type of on-line grading machine needed for high throughput, accuracy, reliability, and total inspection.

The key component of the on-line fruit grading machine is a sensing system that can measure fruit quality by a rapid, nondestructive way and is available for total inspection. Many researchers have explored the possibility of various sensing technologies to measure fruit quality in the on-line fruit grading machine: acoustic technology, 
dielectric property, X-ray technology, and near infrared (NIR) spectroscopy.

Acoustic technology has been applied to assess the internal quality of fruits since the early 1970s. When an acoustic wave is sent to fruits, the reflected or transmitted acoustic wave includes information on acoustic characteristics related to the physical and chemical properties of the fruits (Sun et al., 2010). By analyzing the acoustic characteristics such as attenuation coefficient, transmittance velocity, acoustic impedance, and natural frequency, the internal quality of the fruits can be estimated (Stone et al., 1996; Armstrong et al., 1997; Ozer et al., 1998; Sugiyama et al., 1998; Wang et al., 1999; Diezmalglesias et al., 2004; Jamal et al., 2005).

Dielectric property of a fruit is the ability of the fruit to resist the formation of electric field in the fruit. When an electromagnetic wave is applied to a fruit, a current flows. The amount of total current flowing in the fruit is determined by both capacitive and conductive behaviors of the fruit. The capacitive behavior is frequency-dependent. It is dominated by polarization at low frequency and by dielectric relaxation at high frequency. The electrical conductivity of the fruit is another energy dissipation process through the fruit. This conduction can happen mainly from liquid ionic conduction due to dissolved electrolytes in the water phase of the fruit (Lee et al., 2007). The polarization, relaxation, and conductivity can represent the physical and chemical properties of the fruit. Nelson et al. $(2006,2007,2008)$ measured the dielectric property of honeydew melons, watermelon, and cantaloupe in a frequency range of $10 \mathrm{MHz}-1.8 \mathrm{GHz}$ using a network analyzer and investigated the relationship between the dielectric property and soluble solids content of the fruits.

X-ray emission wavelengths are related to the characteristics of atoms composing of a material. When fruits with different physical and chemical properties are exposed to the X-ray, all of the effects of the physical and chemical properties on the atomic composition are added up and become the total X-ray emission. Thus, the X-ray emission can reflect the properties of the fruits. Some researchers measured the internal defect and soluble solids content of fruits and vegetables using X-ray technology (Diener et al., 1970; Lammertyn et al., 2003; Tollner et al., 2005).

NIR spectroscopy is a rapid, nondestructive technique to measure quality attributes of fruits and vegetables. When a light beam is illuminated to a fruit, an incident light beam is reflected, transmitted, or absorbed. The characteristics of each phenomenon can be different based on the physical and chemical attributes of the fruit (Sun et al., 2010). Thus, the physical and chemical properties of a fruit can be estimated by analyzing the reflected or transmitted spectra using multivariate statistics. NIR spectroscopy technique has been widely used to measure internal qualities of various fruits such as apple, pear, and kiwifruit (McGlone et al., 2007; Liu et al., 2008; Fan et al., 2009; Bobelyn et al., 2010). However, there are some limitations in the application of NIR spectroscopy technique to large or thick-skinned fruits such as watermelons and muskmelons. To measure reliable reflected or transmitted spectra in those fruits, the power of light source should increase drastically and there needs a special care in the arrangement of a light source and a spectrometer probe. Recently, a new configuration (i.e. interactance mode) of a light source and a spectrometer, which is applicable to the fruits through which a light beam cannot penetrate easily, was introduced. In the interactance mode, a light source and a spectrometer are separated and located in some distance $(2-5 \mathrm{~cm})$. When a light beam hits on a fruit, some fraction of the incident light beam transmitting through the internal flesh can be detected by the spectrometer probe on the surface. Thus, this method can measure the spectral characteristics related to internal quality of the fruit with a low power consumption of the light source. There are no reports for predicting melon quality using NIR spectroscopy technology in interactance mode.

The major objective of this study was to investigate the potential of the interactance mode of VIS/NIR spectroscopy technology for predicting soluble solids content (SSC) and firmness of muskmelon. For this, twenty preprocessing methods were applied to the original spectra and then the calibration models for predicting SSC and firmness were tested. The model robustness was examined with the data sets of different harvesting seasons.

\section{Materials and Methods}

\section{Melon samples}

The experiments for collecting the spectral data of muskmelons were conducted three times in different harvesting seasons. Melon samples were taken from commercial greenhouses at Naju, Korea, in February through March, 2009 (experiment 1), June through July, 2009 (experiment 2), and March, 2010 (experiment 3) as 
shown in Table 1. The numbers of samples used in experiments 1,2 , and 3 were 93,104 , and 60 , respectively. The samples were kept in a laboratory at a room temperature $\left(23-25^{\circ} \mathrm{C}\right)$ for 1 day before the experiments. The weight and diameter of each fruit were measured before spectral measurement and were ranged $1.0-2.5 \mathrm{~kg}$ and 11.9 - 17.5 $\mathrm{cm}$, respectively. The SSC and firmness were measured by destructive methods right after spectrum measurement and were in ranges of $4.9-14.2^{\circ} \mathrm{Brix}$ and 6.5 - 42.8 $\mathrm{N}$, respectively.

\section{Spectra measurements}

Interactance spectra were measured at evenly distributed 6 points on an equator of each fruit using a miniature

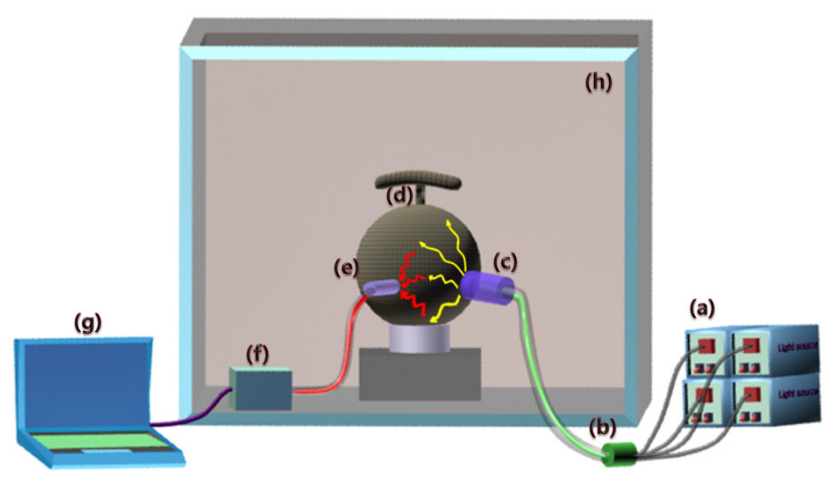

Figure 1. Schematic of the spectral data acquisition system (a: light source, b:optical fiber, c: convex lens, d: fruit sample, e: spectrometer probe, f: spectrometer, g: computer, and h: darkroom chamber). spectrometer (model: USB4000, Ocean Optics, FL, USA) equipped with a CCD array detector. An external light source was constructed with 4 tungsten-halogen lamps of $12 \mathrm{~V} / 100 \mathrm{~W}$ (model: JCR, Ushio Inc., Japan) as shown in Figure 1 . The light emitted by each lamp was emerged into a single optical fiber using a 4 to 1 optical fiber junction so that the maximum power of the light source was close to $400 \mathrm{~W}$. A convex lens was installed at the end of the light guide to focus lighting on a target point of a fruit sample. A collimating lens (model: UV-74, Ocean Optics, FL, USA) was set at the entrance of the optical fiber so that the light photons collected in a wider area could be transported to the spectrometer. The distance between the center of the incident light spot and the center of the collimating lens was maintained at $2 \mathrm{~cm}$. The measurement range of the spectrometer was 400-1160 nm with a resolution of about $0.2 \mathrm{~nm}$. The spectra were collected using the software provided by the manufacturer. The integration time was set to $100 \mathrm{~ms}$ in the software. To build calibration models, the spectra in a range of 475$1100 \mathrm{~nm}$ only were used because the spectra out of that range were too noisy. The spectra measured at the 6 points of each sample were averaged and then the mean spectrum was used as a representative one of each sample.

\section{SSC and firmness measurements}

For the measurement of SSC and firmness by destructive

Table 1. Properties of the fruit samples in experiments 1,2 , and 3

\begin{tabular}{|c|c|c|c|c|}
\hline \multicolumn{2}{|c|}{ Item } & Exp. 1 & Exp. 2 & Exp. 3 \\
\hline \multicolumn{2}{|c|}{ Harvested area } & Naju & Naju & Naju \\
\hline \multicolumn{2}{|c|}{ Cultivar } & Sonata & Sonata & Sonata \\
\hline \multicolumn{2}{|c|}{ Harvested season } & Feb.-Mar., 2009 & June-July, 2009 & March, 2010 \\
\hline \multicolumn{2}{|c|}{ No. of sample } & 93 & 104 & 60 \\
\hline \multirow{3}{*}{ Weight (kg) } & Range & $1.2-2.5$ & $1.0-2.3$ & $1.1-1.6$ \\
\hline & Mean & 1.8 & 1.7 & 1.3 \\
\hline & S.D. & 0.30 & 0.25 & 0.10 \\
\hline \multirow{3}{*}{$\begin{array}{l}\text { Diameter } \\
\quad(\mathrm{cm})\end{array}$} & Range & $12.8-17.5$ & - & $11.9-14.8$ \\
\hline & Mean & 15.2 & - & 12.8 \\
\hline & SD & 1.2 & - & 0.5 \\
\hline \multirow{3}{*}{$\begin{array}{l}\text { SSC } \\
\left({ }^{\circ} \text { Brix }\right)\end{array}$} & Range & $6.0-14.1$ & $4.9-13.9$ & $5.6-14.2$ \\
\hline & Mean & 9.7 & 10.2 & 9.8 \\
\hline & S.D. & 1.87 & 1.74 & 2.21 \\
\hline \multirow{3}{*}{$\begin{array}{l}\text { Firmness } \\
(\mathrm{N})\end{array}$} & Range & $6.7-36.0$ & $13.4-42.8$ & $6.5-42.4$ \\
\hline & Mean & 22.0 & 26.4 & 20.1 \\
\hline & S.D. & 7.10 & 4.39 & 6.22 \\
\hline
\end{tabular}


methods, an equatorial fruit slice with a $2 \mathrm{~cm}$ thickness was cut with a sharp knife. As shown in Figure 2, the firmness of the flesh at the mid-width of the slice was measured by a texture analyzer (MultiTest 1-i, Mecmesin, UK) at the 6 points where the spectral data were collected. A cylindrical probe ( $8 \mathrm{~mm}$ O.D.) equipped at the texture analyzer was moved down into the fruit flesh at a loading speed of $24 \mathrm{~mm} / \mathrm{min}$ to a depth of $15 \mathrm{~mm}$ (ASABE Standards s368.4). The maximum force was recorded as the fruit firmness. When the probe pressed the flesh tissue for firmness measurement, the squeezed juice was taken using a syringe and then the SSC of the juice was measured by a digital refractometer (PR-32 $\alpha$, Atago Co. Ltd., Japan). The SSC and firmness measured at the 6 points of each sample were averaged and the mean value was used as the representative SSC and firmness of each sample.

\section{Data analysis}

The calibration models for the estimation of SSC and firmness were built using partial least square (PLS) regression procedure. To reduce the noise introduced by background effects and other uncertainties, the original spectral data were preprocessed by 20 methods: i) nor-

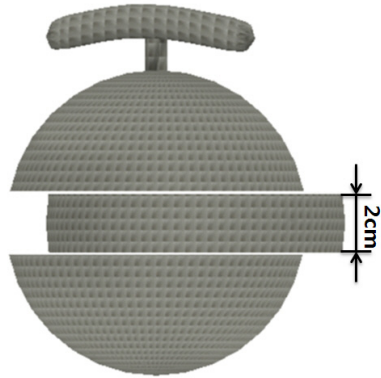

(a)

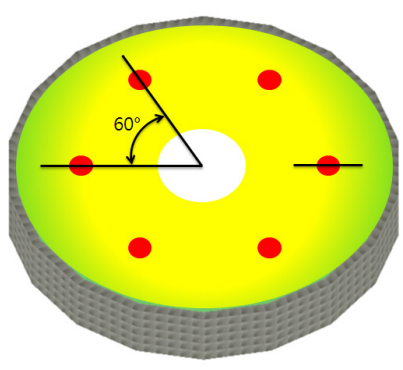

(b)
Figure 2. Location of the points for the measurement of SSC and firmness: (a) an equatorial fruit slice and (b) the measurement points on the slice. malization with mean, maximum, range, ii) multiplicative scatter correction (MSC), iii) standard normal variate (SNV), iv) median filter with 3, 5, 7 segment sizes, v) the first and the second derivatives of Savizky-Golay with 3, 5, 7 smoothing factors, and vi) the first and the second derivatives of Norris Gap with 3, 5, 7 sizes. The original spectral data set and the preprocessed spectral data sets were used to build the calibration models for the estimation of SSC and firmness. The performance of the models were evaluated by a coefficient of determination $\left(\mathrm{R}_{\mathrm{c}}{ }^{2}\right)$ and a standard error (SEC) for calibration and a coefficient of determination $\left(\mathrm{R}_{\mathrm{cv}}{ }^{2}\right)$ and a standard error (SEP) for crossvalidation. The PLS and model evaluation procedures were carried out using The Unscrambler (ver. 9.7, CAMO Process AS, Norway) software package.

\section{Results and Discussion}

\section{Spectra measurements}

The original spectra of fruit samples in experiments 1 , 2 , and 3 are shown in Figure 3. The patterns of the spectral data sets with wavelengths in all experiments are very similar each other. The similar spectral pattern was also observed in the spectra of pear fruits measured in the interactance mode (Suh et al., 2011). As Liu et al. (2010) and Suh et al. (2011) reported, we also believe that the high intensity level at 750-810 $\mathrm{nm}$ may be caused by the high SSC of fruits.

\section{Calibration models for the prediction of SSC}

For the prediction of SSC, the results of PLS calibration and cross validation with raw data and preprocessed data sets are shown in Tables 2, 3, and 4 for experiments $1,2,3$, respectively. As shown in tables, the results are quite different based on the preprocessing methods. In

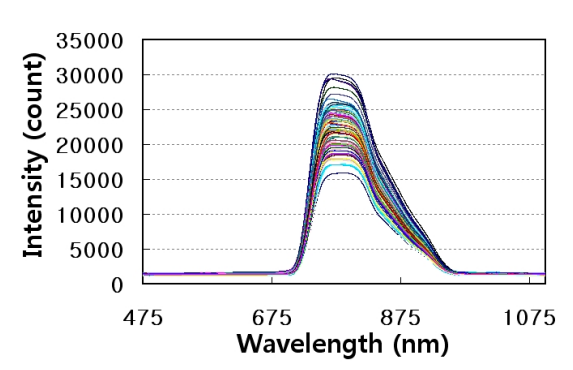

(a)

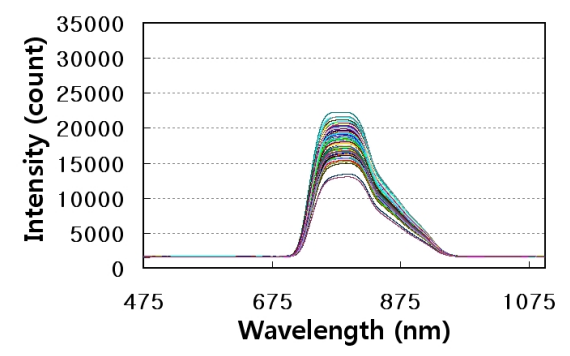

(b)

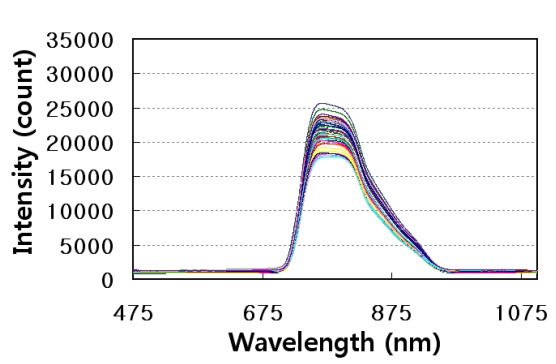

(c)

Figure 3. Original spectral data in (a) experiment 1, (b) experiment 2, and (c) experiment 3. 
Suh et al. A Melon Fruit Grading Machine Using a Miniature VIS/NIR Spectrometer: 1. Calibration Models ... Journal of Biosystems Engineering • Vol. 37, No. 3, 2012 • www.jbeng.org

Table 2. Results of PLS calibration and cross validation for the prediction of SSC in experiment 1

\begin{tabular}{|c|c|c|c|c|c|c|}
\hline \multirow{2}{*}{\multicolumn{3}{|c|}{ Preprocessing }} & \multicolumn{2}{|c|}{ Calibration } & \multicolumn{2}{|c|}{ Cross Validation } \\
\hline & & & $\mathrm{R}_{\mathrm{c}}{ }^{2}$ & SEC ('Brix) & $\mathrm{R}_{\mathrm{cv}}{ }^{2}$ & SEP ( ${ }^{\circ}$ Brix) \\
\hline \multicolumn{3}{|c|}{ Raw data } & 0.858 & 0.67 & 0.705 & 0.98 \\
\hline \multirow{3}{*}{ Normalization } & \multicolumn{2}{|c|}{ Mean } & 0.860 & 0.67 & 0.710 & 0.97 \\
\hline & \multicolumn{2}{|c|}{ Maximum } & 0.832 & 0.73 & 0.732 & 0.93 \\
\hline & \multicolumn{2}{|c|}{ Range } & 0.884 & 0.61 & 0.755 & 0.89 \\
\hline \multicolumn{3}{|c|}{ M S C } & 0.729 & 0.93 & 0.702 & 0.98 \\
\hline \multicolumn{3}{|c|}{ S N V } & 0.744 & 0.90 & 0.691 & 1.00 \\
\hline \multirow{3}{*}{ Median Filter } & \multicolumn{2}{|c|}{ (3) } & 0.840 & 0.71 & 0.700 & 0.99 \\
\hline & \multicolumn{2}{|c|}{ (5) } & 0.838 & 0.72 & 0.699 & 0.99 \\
\hline & \multicolumn{2}{|c|}{ (7) } & 0.837 & 0.72 & 0.701 & 0.99 \\
\hline \multirow{6}{*}{ Savitzky-Golay } & \multirow{3}{*}{ 1st. } & (3) & 0.617 & 1.10 & 0.386 & 1.41 \\
\hline & & (5) & 0.985 & 0.22 & 0.594 & 1.17 \\
\hline & & (7) & 0.910 & 0.53 & 0.627 & 1.10 \\
\hline & \multirow{3}{*}{ 2nd. } & (3) & 0.232 & 1.56 & 0.014 & 2.02 \\
\hline & & (5) & 0.211 & 1.58 & 0.003 & 1.98 \\
\hline & & (7) & 0.336 & 1.45 & 0.012 & 1.90 \\
\hline \multirow{6}{*}{ Norris Gap } & \multirow{3}{*}{ 1st. } & (3) & 0.976 & 0.28 & 0.619 & 1.14 \\
\hline & & (5) & 0.765 & 0.86 & 0.499 & 1.28 \\
\hline & & (7) & 0.942 & 0.43 & 0.667 & 1.05 \\
\hline & \multirow{3}{*}{ 2nd. } & (3) & 0.506 & 1.25 & 0.125 & 1.76 \\
\hline & & (5) & 0.418 & 1.36 & 0.243 & 1.56 \\
\hline & & (7) & 0.990 & 0.17 & 0.412 & 1.40 \\
\hline
\end{tabular}

Table 3. Results of PLS calibration and cross validation for the prediction of SSC in experiment 2

\begin{tabular}{|c|c|c|c|c|c|c|}
\hline \multirow{2}{*}{\multicolumn{3}{|c|}{ Preprocessing }} & \multicolumn{2}{|c|}{ Calibration } & \multicolumn{2}{|c|}{ Cross Validation } \\
\hline & & & $\mathrm{R}_{\mathrm{c}}{ }^{2}$ & SEC ( ${ }^{\circ}$ Brix) & $\mathrm{R}_{\mathrm{cv}}{ }^{2}$ & SEP ( ${ }^{\circ}$ Brix) \\
\hline \multicolumn{3}{|c|}{ Raw data } & 0.810 & 0.73 & 0.717 & 0.89 \\
\hline \multirow{3}{*}{ Normalization } & \multicolumn{2}{|c|}{ Mean } & 0.809 & 0.73 & 0.722 & 0.88 \\
\hline & \multicolumn{2}{|c|}{ Maximum } & 0.762 & 0.81 & 0.698 & 0.92 \\
\hline & \multicolumn{2}{|c|}{ Range } & 0.807 & 0.73 & 0.722 & 0.88 \\
\hline \multicolumn{3}{|c|}{ M S C } & 0.801 & 0.74 & 0.720 & 0.88 \\
\hline \multicolumn{3}{|c|}{ S N V } & 0.790 & 0.76 & 0.723 & 0.88 \\
\hline \multirow{3}{*}{ Median Filter } & \multicolumn{2}{|c|}{ (3) } & 0.803 & 0.74 & 0.719 & 0.89 \\
\hline & \multicolumn{2}{|c|}{ (5) } & 0.803 & 0.74 & 0.720 & 0.88 \\
\hline & \multicolumn{2}{|c|}{ (7) } & 0.802 & 0.74 & 0.720 & 0.89 \\
\hline \multirow{6}{*}{ Savitzky-Golay } & \multirow{3}{*}{ 1st. } & (3) & 0.451 & 1.23 & 0.387 & 1.31 \\
\hline & & (5) & 0.632 & 1.01 & 0.463 & 1.23 \\
\hline & & (7) & 0.935 & 0.42 & 0.653 & 0.99 \\
\hline & \multirow{3}{*}{ 2nd. } & (3) & 0.172 & 1.51 & 0.003 & 1.82 \\
\hline & & (5) & 0.953 & 0.36 & 0.287 & 1.48 \\
\hline & & (7) & 0.934 & 0.43 & 0.245 & 1.56 \\
\hline \multirow{6}{*}{ Norris Gap } & \multirow{3}{*}{ 1st. } & (3) & 0.653 & 0.98 & 0.452 & 1.24 \\
\hline & & (5) & 0.627 & 1.02 & 0.488 & 1.20 \\
\hline & & (7) & 0.900 & 0.53 & 0.587 & 1.10 \\
\hline & \multirow{3}{*}{ 2nd. } & (3) & 0.745 & 0.84 & 0.324 & 1.44 \\
\hline & & (5) & 0.565 & 1.10 & 0.217 & 1.52 \\
\hline & & (7) & 0.453 & 1.23 & 0.305 & 1.39 \\
\hline
\end{tabular}


Suh et al. A Melon Fruit Grading Machine Using a Miniature VIS/NIR Spectrometer: 1. Calibration Models ... Journal of Biosystems Engineering • Vol. 37, No. 3, 2012 • www.jbeng.org

Table 4. Results of PLS calibration and cross validation for the prediction of SSC in experiment 3

\begin{tabular}{|c|c|c|c|c|c|c|}
\hline \multirow{2}{*}{\multicolumn{3}{|c|}{ Preprocessing }} & \multicolumn{2}{|c|}{ Calibration } & \multicolumn{2}{|c|}{ Cross Validation } \\
\hline & & & $\mathrm{R}_{\mathrm{c}}{ }^{2}$ & SEC ( ${ }^{\circ}$ Brix) & $\mathrm{R}_{\mathrm{cv}}{ }^{2}$ & SEP ( ${ }^{\circ}$ Brix) \\
\hline \multicolumn{3}{|c|}{ Raw data } & 0.799 & 0.97 & 0.693 & 1.21 \\
\hline \multirow{3}{*}{ Normalization } & \multicolumn{2}{|c|}{ Mean } & 0.810 & 0.94 & 0.660 & 1.28 \\
\hline & \multicolumn{2}{|c|}{ Maximum } & 0.789 & 0.99 & 0.675 & 1.25 \\
\hline & \multicolumn{2}{|c|}{ Range } & 0.799 & 0.97 & 0.652 & 1.29 \\
\hline \multicolumn{3}{|c|}{ M S C } & 0.773 & 1.03 & 0.651 & 1.28 \\
\hline \multicolumn{3}{|c|}{ S N V } & 0.773 & 1.03 & 0.651 & 1.28 \\
\hline \multirow{3}{*}{ Median Filter } & \multicolumn{2}{|c|}{ (3) } & 0.793 & 0.98 & 0.695 & 1.20 \\
\hline & \multicolumn{2}{|c|}{ (5) } & 0.793 & 0.98 & 0.696 & 1.20 \\
\hline & \multicolumn{2}{|c|}{ (7) } & 0.792 & 0.98 & 0.696 & 1.20 \\
\hline \multirow{6}{*}{ Savitzky-Golay } & \multirow{3}{*}{1 st. } & (3) & 0.803 & 0.96 & 0.429 & 1.66 \\
\hline & & (5) & 0.708 & 1.17 & 0.459 & 1.61 \\
\hline & & (7) & 0.963 & 0.41 & 0.533 & 1.52 \\
\hline & \multirow{3}{*}{ 2nd. } & (3) & 0.338 & 1.75 & 0.107 & 2.08 \\
\hline & & (5) & 0.348 & 1.74 & 0.061 & 2.17 \\
\hline & & (7) & 0.621 & 1.33 & 0.210 & 1.98 \\
\hline \multirow{6}{*}{ Norris Gap } & \multirow{3}{*}{ 1st. } & (3) & 0.719 & 1.14 & 0.457 & 1.61 \\
\hline & & (5) & 0.995 & 0.15 & 0.554 & 1.47 \\
\hline & & (7) & 0.598 & 1.37 & 0.420 & 1.67 \\
\hline & \multirow{3}{*}{ 2nd. } & (3) & 0.419 & 1.64 & 0.179 & 1.98 \\
\hline & & (5) & 0.457 & 1.59 & 0.193 & 1.96 \\
\hline & & (7) & 0.420 & 1.64 & 0.131 & 2.05 \\
\hline
\end{tabular}

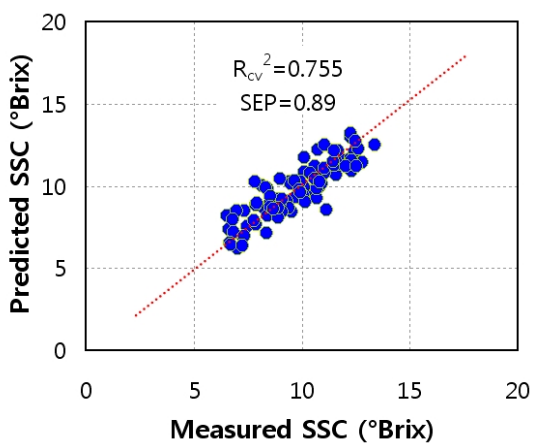

(a)

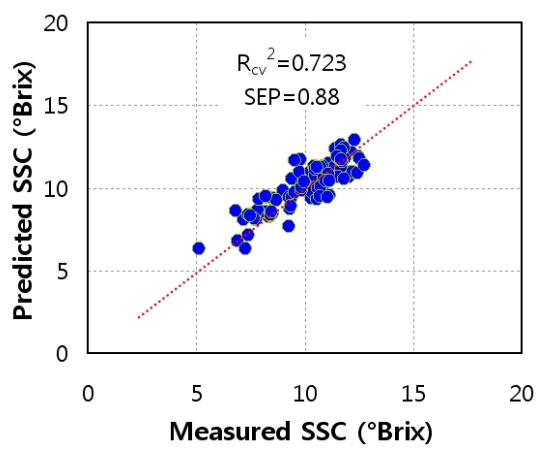

(b)

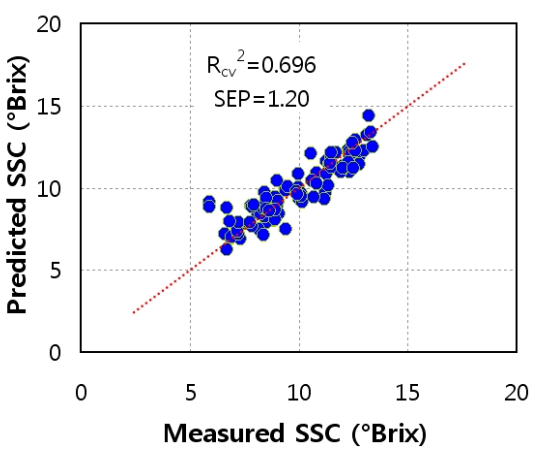

(c)

Figure 4. Measured versus predicted SSC of the best models in (a) experiment 1 with the preprocessing of normalization (range), (b) experiment 2 with the preprocessing of SNV, and (c) experiment 3 with the preprocessing of median filter (5 smooth factors).

general, the preprocessing methods of normalization, MSC, SNV, and median filter contribute to improve the performance of the models. However, the Savitzky-Golay and Norris Gap derivatives do not. Some preprocessing methods made the results worse, compared to the results of the models using the original data set.

The best models in experiments 1, 2, 3 are found when the data are preprocessed by normalization with range, SNV, and median filter with 5 smooth factors, respectively. The $\mathrm{R}_{\mathrm{cv}}{ }^{2}$ values of the best models in experiments 1,2 , and
3 are 0.755 (SEP $\left.=0.89^{\circ} \mathrm{Brix}\right), 0.723\left(\mathrm{SEP}=0.88^{\circ} \mathrm{Brix}\right)$, and 0.696 (SEP $=1.20^{\circ} \mathrm{Brix}$ ), respectively. This prediction levels are slightly lower than those for the fruits with smooth and thin skin such as apple and pear (generally, $\mathrm{R}_{\mathrm{cv}}{ }^{2}$ $=$ more than $0.8, \mathrm{SEP}=$ below $0.5^{\circ} \mathrm{Brix}$ ). We think that light interference by unevenly distributed melon nets and thick skin might cause the capability of spectroscopic technology for the prediction of SSC low.

The robustness of the best models selected in experiments 1, 2, 3 was tested. The performance of the models 
was evaluated with the spectral data sets collected in the same cultivar and harvested area, but in different harvesting seasons (Table 1). As shown in Table 5, the models are generally lacking in robustness. The highest coefficient of determination in the robustness tests, $\mathrm{R}_{\mathrm{rt}}{ }^{2}=0.650$ (SEP = $1.03{ }^{\circ} \mathrm{Brix}$ ), was found when the best model of experiment 3 was evaluated with the data set of experiment 2 .

One of the major limitations of spectroscopic technology with the analysis of spectral data by multivariate statistics is lacking in robustness of calibration models. Except for a main factor (i.e. SSC) to be considered in calibration models, other uncertain factors such as plant age, crop load, light effect, position in the plant and the greenhouse, nutrition variability, fruit age, seasonal variability can affect the characteristics of the spectra by changing the fruit morphology and microstructure (Penchaiya et al., 2009). Some researchers reported that the prediction error can increase when a calibration model is applied to the data sets of different harvesting seasons and areas (Guthrie et al., 1998; Nicolari et al., 2007; Saeys et al., 2008).

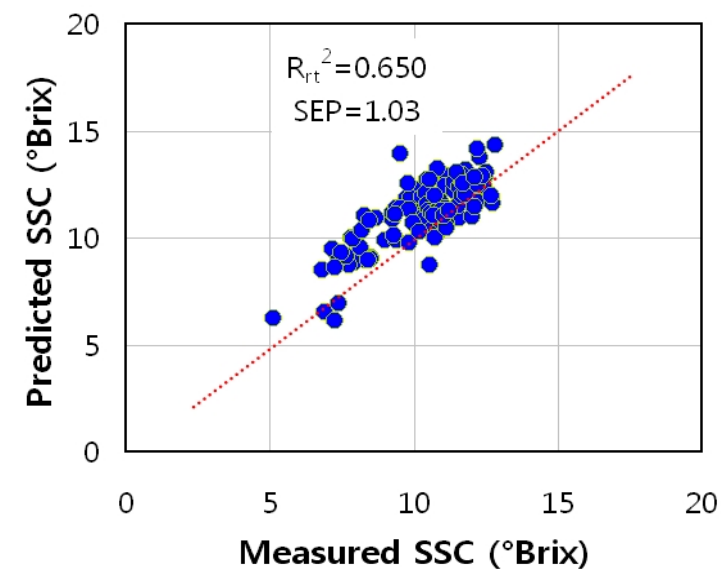

Figure 5. Measured versus predicted SSC in the robustness test using the data set of experiment 3 for building the model and the data set of experiment 2 for validation.

\section{Calibration models for the prediction of firmness}

In the prediction of firmness, the performance of the models with the preprocessed data sets is similar to or worse than that of the models with the raw data in all experiments (Tables 6, 7, 8). As in the prediction of SSC, the preprocessing techniques of the Savitzky-Golay and Norris Gap derivatives are not useful for the prediction of firmness. The best models in experiments 1, 2, 3 are found at the raw data, the median filter preprocessing $(7$ and 3 smooth factors), respectively. The $\mathrm{R}_{\mathrm{cv}}{ }^{2}$ values of the best models in experiments 1,2 , and 3 are $0.715(\mathrm{SEP}=3.63 \mathrm{~N})$, $0.451(\mathrm{SEP}=3.11 \mathrm{~N})$, and $0.443(\mathrm{SEP}=4.53 \mathrm{~N})$, respectively.

Table 9 shows the test results of the model robustness in the prediction of firmness. As in the model robustness for the prediction of SSC (Table 5), the robustness of the models needs to be improved for the application of the calibration models to the data sets of different harvesting seasons. The highest $\mathrm{R}_{\mathrm{rt}}{ }^{2}$ is $0.404(\mathrm{SEP}=5.30 \mathrm{~N})$ when the best model of experiment 3 is applied to the data set of experiment 1 .

The performance of the models for predicting fruit firmness (Tables 6-8) using VIS/NIR spectroscopy is worse than that for predicting SSC (Tables 2-4) in all experiments. Lu (2004) reported that this unsatisfactory result for predicting firmness might be caused by the measurement principle of a VIS/NIR spectrometer. When a light beam falls on a fruit, some fraction is reflected on the surface and the rest is absorbed or scattered into the fruit tissue by interacting with biological materials. The light absorption is related to chemical properties in the fruit such as sugar, acid, and water. On the other hand, the light scattering is affected by physical properties such as density and cell structure. A VIS/NIR spectrometer fundamentally measures the amount of light reflected from a sample, not the light scattered in the sample. Therefore, VIS/NIR spectroscopy technology may be limited to the measurement of physical properties such as firmness.

Table 5. Robustness of the models for the prediction of SSC

\begin{tabular}{|c|c|c|c|c|c|c|}
\hline \multirow{3}{*}{ Predicted data } & \multicolumn{6}{|c|}{ Data for building models } \\
\hline & \multicolumn{2}{|c|}{ Exp. 1} & \multicolumn{2}{|c|}{ Exp. 2} & \multicolumn{2}{|c|}{ Exp. 3} \\
\hline & $\mathrm{R}_{\mathrm{rt}}^{2}$ & SEP ( ${ }^{\circ}$ Brix) & $\mathrm{R}_{\mathrm{rt}}^{2}$ & SEP ( ${ }^{\circ}$ Brix) & $\mathrm{R}_{\mathrm{rt}}^{2}$ & SEP ( ${ }^{\circ}$ Brix) \\
\hline Exp. 1 & - & - & 0.483 & 1.51 & 0.265 & 2.29 \\
\hline Exp. 2 & 0.161 & 1.64 & - & - & 0.650 & 1.03 \\
\hline Exp. 3 & 0.508 & 1.51 & 0.404 & 1.68 & - & - \\
\hline
\end{tabular}


Suh et al. A Melon Fruit Grading Machine Using a Miniature VIS/NIR Spectrometer: 1. Calibration Models ... Journal of Biosystems Engineering • Vol. 37, No. 3, 2012 • www.jbeng.org

Table 6. Results of PLS calibration and cross validation for the prediction of firmness in experiment 1

\begin{tabular}{|c|c|c|c|c|c|c|}
\hline \multirow{2}{*}{\multicolumn{3}{|c|}{ Preprocessing }} & \multicolumn{2}{|c|}{ Calibration } & \multicolumn{2}{|c|}{ Cross Validation } \\
\hline & & & $\mathrm{R}_{\mathrm{c}}{ }^{2}$ & SEC & $\mathrm{R}_{\mathrm{cv}}{ }^{2}$ & SEP \\
\hline \multicolumn{3}{|c|}{ Raw data } & 0.762 & 3.31 & 0.715 & 3.61 \\
\hline \multirow{3}{*}{ Normalization } & \multicolumn{2}{|c|}{ Mean } & 0.748 & 3.41 & 0.709 & 3.65 \\
\hline & \multicolumn{2}{|c|}{ Maximum } & 0.755 & 3.36 & 0.714 & 3.62 \\
\hline & \multicolumn{2}{|c|}{ Range } & 0.866 & 3.39 & 0.712 & 3.63 \\
\hline \multicolumn{3}{|c|}{ M S C } & 0.740 & 3.46 & 0.701 & 3.70 \\
\hline \multicolumn{3}{|c|}{ S N V } & 0.746 & 3.42 & 0.706 & 3.66 \\
\hline \multirow{3}{*}{ Median Filter } & \multicolumn{2}{|c|}{ (3) } & 0.762 & 3.31 & 0.715 & 3.61 \\
\hline & \multicolumn{2}{|c|}{ (5) } & 0.762 & 3.31 & 0.715 & 3.61 \\
\hline & \multicolumn{2}{|c|}{ (7) } & 0.762 & 3.31 & 0.715 & 3.61 \\
\hline \multirow{6}{*}{ Savitzky-Golay } & \multirow{3}{*}{ 1st. } & (3) & 0.738 & 3.48 & 0.603 & 4.26 \\
\hline & & (5) & 0.731 & 3.52 & 0.628 & 4.13 \\
\hline & & (7) & 0.817 & 2.90 & 0.678 & 3.85 \\
\hline & \multirow{3}{*}{ 2nd. } & (3) & 0.877 & 2.38 & 0.324 & 6.09 \\
\hline & & (5) & 0.918 & 1.95 & 0.387 & 5.59 \\
\hline & & (7) & 0.799 & 3.05 & 0.375 & 5.62 \\
\hline \multirow{6}{*}{ Norris Gap } & \multirow{3}{*}{ 1st. } & (3) & 0.738 & 3.48 & 0.603 & 4.26 \\
\hline & & (5) & 0.825 & 2.83 & 0.668 & 3.91 \\
\hline & & (7) & 0.830 & 2.80 & 0.715 & 3.61 \\
\hline & \multirow{3}{*}{ 2nd. } & (3) & 0.976 & 1.05 & 0.378 & 5.43 \\
\hline & & (5) & 0.628 & 4.14 & 0.520 & 4.68 \\
\hline & & (7) & 0.526 & 4.67 & 0.468 & 4.93 \\
\hline
\end{tabular}

Table 7. Results of PLS calibration and cross validation for the prediction of firmness in experiment 2

\begin{tabular}{|c|c|c|c|c|c|c|}
\hline \multirow{2}{*}{\multicolumn{3}{|c|}{ Preprocessing }} & \multicolumn{2}{|c|}{ Calibration } & \multicolumn{2}{|c|}{ Cross Validation } \\
\hline & & & $\mathrm{R}_{\mathrm{c}}{ }^{2}$ & SEC & $\mathrm{R}_{\mathrm{cv}}{ }^{2}$ & SEP \\
\hline \multicolumn{3}{|c|}{ Raw data } & 0.719 & 2.18 & 0.439 & 3.16 \\
\hline \multirow{3}{*}{ Normalization } & \multicolumn{2}{|c|}{ Mean } & 0.707 & 2.23 & 0.421 & 3.21 \\
\hline & \multicolumn{2}{|c|}{ Maximum } & 0.661 & 2.39 & 0.385 & 3.33 \\
\hline & \multicolumn{2}{|c|}{ Range } & 0.608 & 2.57 & 0.378 & 3.33 \\
\hline \multicolumn{3}{|c|}{ M S C } & 0.686 & 2.30 & 0.407 & 3.25 \\
\hline \multicolumn{3}{|c|}{$S \mathrm{NV}$} & 0.691 & 2.29 & 0.409 & 3.24 \\
\hline \multirow{3}{*}{ Median Filter } & \multicolumn{2}{|c|}{ (3) } & 0.686 & 2.31 & 0.449 & 3.12 \\
\hline & \multicolumn{2}{|c|}{ (5) } & 0.682 & 2.32 & 0.450 & 3.11 \\
\hline & \multicolumn{2}{|c|}{ (7) } & 0.678 & 2.33 & 0.451 & 3.11 \\
\hline \multirow{6}{*}{ Savitzky-Golay } & \multirow{3}{*}{ 1st. } & (3) & 0.236 & 3.59 & 0.151 & 3.81 \\
\hline & & (5) & 0.209 & 3.66 & 0.153 & 3.79 \\
\hline & & (7) & 0.381 & 3.23 & 0.200 & 3.73 \\
\hline & \multirow{3}{*}{ 2nd. } & (3) & 0.210 & 3.65 & 0.003 & 4.38 \\
\hline & & (5) & 0.945 & 0.96 & 0.255 & 3.79 \\
\hline & & (7) & 0.278 & 3.49 & 0.017 & 4.31 \\
\hline \multirow{6}{*}{ Norris Gap } & \multirow{3}{*}{ 1st. } & (3) & 0.236 & 3.58 & 0.151 & 3.81 \\
\hline & & (5) & 0.441 & 3.06 & 0.202 & 3.75 \\
\hline & & (7) & 0.384 & 3.21 & 0.209 & 3.71 \\
\hline & \multirow{3}{*}{ 2nd. } & (3) & 0.198 & 3.66 & 0.001 & 4.49 \\
\hline & & (5) & 0.347 & 3.31 & 0.068 & 4.09 \\
\hline & & (7) & 0.315 & 3.38 & 0.131 & 3.88 \\
\hline
\end{tabular}


Suh et al. A Melon Fruit Grading Machine Using a Miniature VIS/NIR Spectrometer: 1. Calibration Models ... Journal of Biosystems Engineering • Vol. 37, No. 3, 2012 • www.jbeng.org

Table 8. Results of PLS callibration and cross validation for the prediction of firmness in experiment 3

\begin{tabular}{|c|c|c|c|c|c|c|}
\hline \multirow{2}{*}{\multicolumn{3}{|c|}{ Preprocessing }} & \multicolumn{2}{|c|}{ Calibration } & \multicolumn{2}{|c|}{ Cross Validation } \\
\hline & & & $\mathrm{R}_{\mathrm{c}}{ }^{2}$ & SEC & $\mathrm{R}_{\mathrm{cv}}{ }^{2}$ & SEP \\
\hline \multicolumn{3}{|c|}{ Raw data } & 0.622 & 3.67 & 0.442 & 4.53 \\
\hline \multirow{3}{*}{ Normalization } & \multicolumn{2}{|c|}{ Mean } & 0.561 & 3.92 & 0.416 & 4.61 \\
\hline & \multicolumn{2}{|c|}{ Maximum } & 0.474 & 4.32 & 0.372 & 4.75 \\
\hline & \multicolumn{2}{|c|}{ Range } & 0.473 & 4.33 & 0.368 & 4.76 \\
\hline \multicolumn{3}{|c|}{ M S C } & 0.593 & 3.80 & 0.377 & 4.79 \\
\hline \multicolumn{3}{|c|}{ S N V } & 0.591 & 3.81 & 0.372 & 4.81 \\
\hline \multirow{3}{*}{ Median Filter } & \multicolumn{2}{|c|}{ (3) } & 0.612 & 3.71 & 0.443 & 4.53 \\
\hline & \multicolumn{2}{|c|}{ (5) } & 0.611 & 3.72 & 0.439 & 4.53 \\
\hline & \multicolumn{2}{|c|}{ (7) } & 0.609 & 3.73 & 0.436 & 4.54 \\
\hline \multirow{6}{*}{ Savitzky-Golay } & \multirow{3}{*}{ 1st. } & (3) & 0.806 & 2.63 & 0.366 & 4.86 \\
\hline & & (5) & 0.474 & 4.32 & 0.311 & 4.99 \\
\hline & & (7) & 0.952 & 1.31 & 0.421 & 4.70 \\
\hline & \multirow{3}{*}{ 2nd. } & (3) & 0.233 & 5.22 & 0.007 & 6.32 \\
\hline & & (5) & 0.311 & 4.95 & 0.013 & 6.34 \\
\hline & & (7) & 0.358 & 4.78 & 0.010 & 6.41 \\
\hline \multirow{6}{*}{ Norris Gap } & \multirow{3}{*}{ 1st. } & (3) & 0.806 & 2.63 & 0.366 & 4.86 \\
\hline & & (5) & 0.892 & 1.96 & 0.419 & 4.70 \\
\hline & & (7) & 0.401 & 4.61 & 0.278 & 5.11 \\
\hline & \multirow{3}{*}{ 2nd. } & (3) & 0.309 & 4.95 & 0.010 & 6.37 \\
\hline & & (5) & 0.942 & 1.44 & 0.227 & 5.61 \\
\hline & & (7) & 0.279 & 5.06 & 0.000 & 6.63 \\
\hline
\end{tabular}

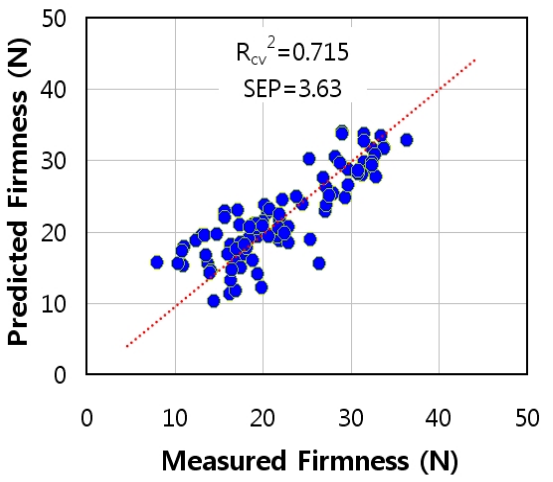

(a)

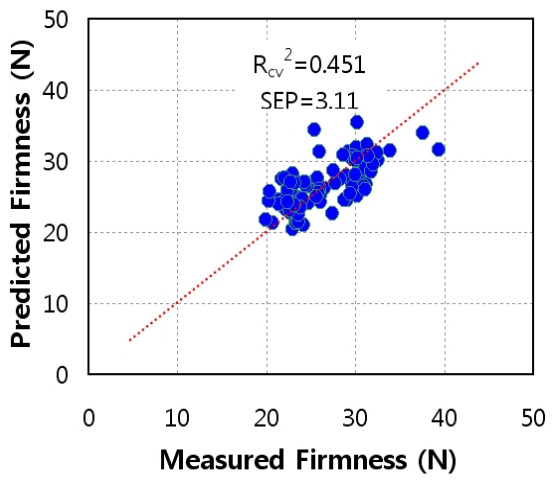

(b)

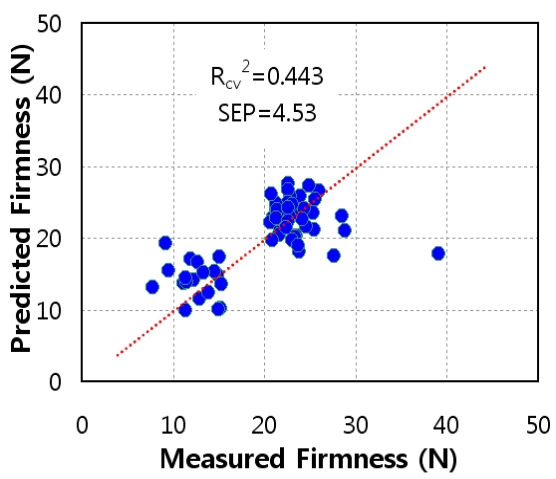

(c)

Figure 6. Measured versus predicted firmness of the best models in (a) experiment 1 with the raw data, (b) experiment 2 with the preprocessing of median filter (7 smooth factors), and (c) experiment 3 with the preprocessing of median filter (3 smooth factors).

\section{Table 9. Robustness of the models for the prediction of firmness}

\begin{tabular}{cccccccc} 
& \multicolumn{9}{c}{ Data for building models } \\
\cline { 2 - 7 } Predicted data & \multicolumn{3}{c}{ Exp. 1 } & \multicolumn{3}{c}{ Exp. 2 } & \multicolumn{2}{c}{ Exp. 3 } \\
\cline { 2 - 8 } & $\mathrm{R}_{\mathrm{rt}}{ }^{2}$ & SEP $(\mathrm{N})$ & $\mathrm{R}_{\mathrm{rt}}{ }^{2}$ & SEP $(\mathrm{N})$ & $\mathrm{R}_{\mathrm{rt}}{ }^{2}$ & SEP (N) \\
Exp. 1 & - & - & 0.188 & 6.54 & 0.404 & 5.30 \\
Exp. 2 & 0.209 & 4.27 & - & - & 0.165 & 4.27 \\
Exp. 3 & 0.029 & 6.65 & 0.185 & 5.61 & - & - \\
\hline
\end{tabular}




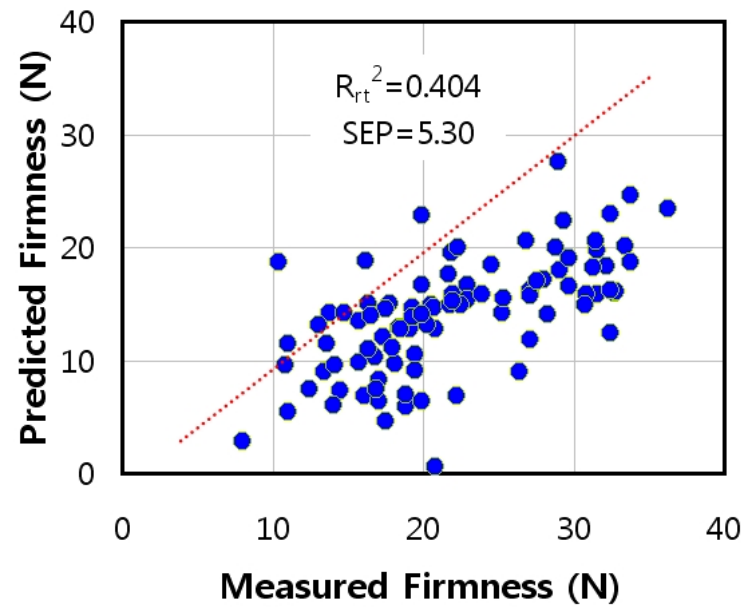

Figure 7. Measured versus predicted firmness in the robustness test using the data set of experiment 3 for building the model and the data set of experiment 1 for validation.

The interactance mode used in this study is a new trial for capturing both light absorption and light scattering information from fruit samples to predict both SSC and firmness simultaneously. This paper mainly focused on the VIS/NIR spectral data acquisition system and the calibration models using the data sets measured in the interactance mode. Some factors to be considered in designing a melon fruit grading machine using the interactance mode of VIS/NIR spectroscopy technology are discussed in the other paper (Suh et al, 2012).

\section{Conclusions}

The potential of interactance mode of VIS/NIR spectroscopy technology for the estimation of SSC and firmness of muskmelons was investigated. The spectral data were preprocessed by 20 methods. In the prediction of SSC, the performance of the models using the preprocessed data was better than that using the original data. The highest $\mathrm{R}_{\mathrm{cv}}{ }^{2}$ was 0.755 (SEP $=0.89^{\circ} \mathrm{Brix}$ ) with the preprocessing of normalization with range in experiment 1 . The highest $\mathrm{R}_{\mathrm{rt}}{ }^{2}=0.650$ (SEP=1.03 ${ }^{\circ} \mathrm{Brix}$ ) was found when the best model of experiment 3 was evaluated with the data set of experiment 2 . The preprocessing technique was not much useful for the prediction of firmness. The highest $\mathrm{R}_{\mathrm{cv}}{ }^{2}$ of $0.715(\mathrm{SEP}=3.63 \mathrm{~N}$ ) was found when no preprocessing was applied in experiment 1 . The highest $\mathrm{R}_{\mathrm{rt}}{ }^{2}$ is 0.404 $(\mathrm{SEP}=5.30 \mathrm{~N})$ when the best model of experiment 3 is applied to the data set of experiment 1 . From the test results, it can be concluded that the interactance mode of
VIS/NIR spectroscopy technology has a great potential to measure SSC and firmness of thick-skinned muskmelons.

\section{Conflict of Interest}

No potential conflict of interest relevant to this article was reported.

\section{Acknowledgements}

This work was supported by Basic Science Research Program through the National Research Foundation of Korea (NRF) funded by the Ministry of Education, Science and Technology (MEST) (KRF-2007-314-D00343).

\section{References}

Armstrong, P. R., M. L. Stone and G. H. Brusewitz. 1997. Nondestructive acoustic and compression measurements of watermelon for internal damage detection. Applied Engineering in Agriculture 13(5):641-645.

Bobelyn, E., A. S. Serban, M. Nicu, J. Lammertyn, B. M. Nicolai and W. Saeys. 2010. Postharvest quality of apple predicted by NIR-spectroscopy: study of the effect of biological variability on spectra and model performance. Postharvest Biology and Technology 55(3): 133-143.

Diener, R. G., J. P. Mitchell and M. L. Rhoten. 1970. Using an X-ray image scan to sort bruised apples. Agricultural Engineering 51(6):356-361.

Diezma-Iglesias, B., M. Ruiz-Altisent and P. Barreiro, 2004. Detection of internal quality in seedless watermelon by acoustic impulse response. Biosystems Engineering 88(2):221-230.

Fan, G. Q., J. W. Zha, R. Du and L. Gao. 2009. Determination of soluble solids and firmness of apples by Vis/NIR transmittance. Journal of Food Engineering 93(4):416420.

Guthrie, J., B. Wedding and K. Walsh. 1998. Robustness of NIR calibrations for soluble solids in intact melon and pineapple. Journal of Near Infrared Spectroscopy 6: 259-265.

Jamal, N., Y. Ying, J. Wang and X, Rao. 2005. Finite element models of watermelon and their applications. Transactions of the CSAE 21(1):17-22. 
Lammertyn, J., T. Dresselaers, P. H. Van, P. Jancsòk, M. Wevers and B. M. Nicolaï. 2003. MRI and X-ray CT study of spatial distribution of core breakdown in 'Conference' pears. Magnetic Resonance Imaging 21: 805-815.

Lee, K. H., N. Zhang, W. B. Kuhn and G. J. Kluitenberg. 2007. A frequency-response permittivity sensor for simultaneous measurement of multiple soil properties: part 1. the frequency-response method. Transactions of the ASABE 50(6):2315-2326.

Liu, Y., X. Sun and A. Ouyang. 2010. Nondestructive measurement of soluble solid content of navel orange fruit by visible-NIR spectrometric technique with PLSR and PCA-BPNN. LWT-Food Science and Technology 43: 602-607.

Liu, Y. D., X. M. Chen and A. G. Ouyang. 2008. Nondestructive determination of pear internal quality indices by visible and near-infrared spectrometry. LWT Food Science and Technology 41(9):1720-1725.

Lu, R. 2004. Multispectral imaging for predicting firmness and soluble solids content of apple fruit. Postharvest Biology and Technology 31:147-157.

McGlone, V. A., C. J. Clark and R. B. Jordan. 2007. Comparing density and VNIR methods for predicting quality parameters of yellow-fleshed kiwifruit (Actinidia chinensis). Postharvest Biology and Technology 46 (1):1-9.

Nelson, S. O., S. Trabelsi and S. J. Kays. 2006. Dielectric spectroscopy of honeydew melons from $10 \mathrm{MHz}$ to $1.8 \mathrm{GHz}$ for quality sensing. Transactions of the ASABE 49(6):1977-1981.

Nelson, S. O., W. Guo, S. Trabelsi and S. J. Kays. 2007. Dielectric spectroscopy of watermelons for quality sensing. Measurement Science and Technology 18: 1887-1892.

Nelson, S. O., S. Trabelsi and S. J. Kays. 2008. Dielectric spectroscopy of melons for potential quality sensing. Transactions of the ASABE 51(6):2209-2214.

Nicolai, B. M., K. Beullens, E. Bobelyn, A. Peirs, W. Saeys, K. I. Theron and J. Lammertyn. 2007. Nondestructive measurement of fruit and vegetable quality by means of NIR spectroscopy: a review. Postharvest Biology and Technology 46:99-118.
Ozer, N., B. A. Engel and J. E. Simon. 1998. A multiple impact approach for nondestructive measurement of fruit firmness and maturity. Transactions of the ASAE 41(3):871-876.

Penchaiya, P., E. Bobelyn, B. E. Verlinden, B. M. Nicolai and W. Saeys. 2009. Non-destructive measurement of firmness and soluble solids content in bell pepper using NIR spectroscopy. Journal of Food Engineering 94: 267-273.

Saeys, W., K. Beullens, J. Lammertyn, H. Ramon and T. Naes. 2008. Increasingrobustness against changes in the interferent structure by incorporating priorinformation in the augmented classical least-squares framework. Anal. Chem. 80(13):4951-4959.

Stone, M. L., P. R. Armstrong, X. Zhang, G. H. Brusewitz and D. D. Chen. 1996. Watermelon maturity determination in the field using acoustic impulse impedance techniques. Transactions of the ASAE 39(6):2325-2330.

Sugiyama, J., T. Katsural, J. Hong, H. Koyama and K. Mikuriya. 1998. Melon ripeness monitoring by a portable firmness tester. Transactions of the ASAE 41(1):121-127.

Suh, S. R., K. H. Lee, S. H. Yu, S. N. Yoo and Y. S. Choi. 2011. Comparison of performance of measuring of VIS/NIR spectroscopic spectrum to predict soluble solids content and 'Shingo' pear. Journal of Biosystems Engineering 36(2):130-139.

Suh, S. R., K. H. Lee, S. H. Yu, H. S. Shin, S. N. Yoo and Y. S. Choi. 2012. A melon fruit grading machine using a miniature VIS/NIR spectrometer: 2. Design factors for optimal interactance measurement setuo. Journal of Biosystems Engineering 37(3):177-183.

Sun, T., K. Huang, H. Xu and Y. Ying. 2010. Research advances in nondestructive determination of internal quality in watermelon/melon: A review. Journal of Food Engineering 100:569-577.

Tollner, E. W., R. D. Gitaitis, K. W. Seebold and B. W. Maw. 2005. Experiences with a food product X-ray inspection system for classifying onions. Applied Engineering in Agriculture 21(5):907-912.

Wang, S., Q. Jiao and J. Ji. 1999. An impulse response method of nondestructive inspection of the ripeness of watermelon. Transactions of the CSAE 15(3):241245. 